University of Wollongong

Research Online

Australian Institute for Innovative Materials -

Papers

Australian Institute for Innovative Materials

$1-1-2017$

\title{
Effective area and charge density of iridium oxide neural electrodes
}

Alexander R. Harris

University of Wollongong, alexh@uow.edu.au

Antonio G. Paolini

La Trobe University, a.paolini@latrobe.edu.au

Gordon G. Wallace

University of Wollongong, gwallace@uow.edu.au

Follow this and additional works at: https://ro.uow.edu.au/aiimpapers

Part of the Engineering Commons, and the Physical Sciences and Mathematics Commons

Research Online is the open access institutional repository for the University of Wollongong. For further information contact the UOW Library: research-pubs@uow.edu.au 


\title{
Effective area and charge density of iridium oxide neural electrodes
}

\author{
Abstract \\ The effective electrode area and charge density of iridium metal and anodically activated iridium has been \\ measured by optical and electrochemical techniques. The degree of electrode activation could be \\ assessed by changes in electrode colour. The reduction charge, activation charge, number of activation \\ pulses and charge density were all strongly correlated. Activated iridium showed slow electron transfer \\ kinetics for reduction of a dissolved redox species. At fast voltammetric scan rates the linear diffusion \\ electroactive area was unaffected by iridium activation. At slow voltammetric scan rates, the steady state \\ diffusion electroactive area was reduced by iridium activation. The steady state current was consistent \\ with a ring electrode geometry, with lateral resistance reducing the electrode area. Slow electron transfer \\ on activated iridium would require a larger overpotential to reduce or oxidise dissolved species in tissue, \\ limiting the electrodes charge capacity but also reducing the likelihood of generating toxic species in vivo.

\section{Disciplines} \\ Engineering | Physical Sciences and Mathematics \\ Publication Details \\ Harris, A. R., Paolini, A. G. \& Wallace, G. G. (2017). Effective area and charge density of iridium oxide \\ neural electrodes. Electrochimica Acta, 230 285-292.
}


Effective Area and Charge Density of Dextran Sulphate Doped PEDOT Modified Electrodes

Alexander R. Harris ${ }^{1}$, Paul J. Molino², Robert M.I. Kapsa ${ }^{2,3}$, Graeme M. Clark ${ }^{4}$, Antonio G. Paolini ${ }^{5,6}$, Gordon G. Wallace ${ }^{2}$

${ }^{1}$ HEARing CRC, Intelligent Polymer Research Institute, University of Wollongong, Wollongong, NSW, 2522, Australia

${ }^{2}$ ARC Centre of Excellence for Electromaterials Science, Intelligent Polymer Research Institute, University of Wollongong, NSW 2522, Australia.

${ }^{3}$ Department of Neurosciences, St Vincents Hospital, Melbourne and Department of Medicine University of Melbourne, Fitzroy, Victoria, 3065, Australia

${ }^{4}$ School of Engineering, University of Melbourne, Parkville, Victoria, 3010, Australia

${ }^{5}$ School of Health Science, RMIT University, Bundoora, Victoria, 3083, Australia

${ }^{6}$ School of Psychology and Public Health, La Trobe University, Bundoora, Victoria, 3086, Australia

Email: alexrharris@gmail.com 


\begin{abstract}
The performance of neural electrodes over chronic periods is poor with degrading signal-to-noise ratio and low biocompatibility. Consequently, electrodes require modification to improve their performance, biostability and biocompatibility. A large variety of doped conducting polymers have been proposed for optimising neural electrodes, but to date, none have achieved the required biostability and biocompatibility necessary for human application. Dextran sulfate is used as an antithrombotic and may be of use in improving neural electrode biocompatibility. Poly-3,4-ethylenedioxythiophene was successfully doped with dextran sulfate (PEDOT-DS) by electropolymerisation on neural electrode arrays. Deposited films increased the electrode area and displayed a rough morphology compared to uncoated electrodes. Electrode area and charge density were obtained using microscopy and reduction of $\mathrm{Ru}\left(\mathrm{NH}_{3}\right)_{6}{ }^{3+}$. Deposition charge, geometrical and linear diffusion electroactive areas were strongly correlated with deposition time. The charge density calculated from the geometrical area was greater on PEDOT-DS modified electrodes than unmodified and PEDOT-para-toluene sulfonate (PEDOTpTs) modified electrodes. The charge density calculated from the linear diffusion electroactive area was smaller on PEDOT-DS modified electrodes than unmodified and PEDOT-pTs modified electrodes. The charge density of the PEDOT-DS modified electrodes was dependant on the electrode area.
\end{abstract}

\title{
Keywords
}

Electroactive polymer; Surface analysis; Charge Density 


\section{Introduction}

Implantable medical devices are increasingly being used for the treatment and control of disease. Many of these bionic implants incorporate electrodes for recording and stimulation of excitable cells. A major limitation in the performance of these devices is fouling and encapsulation by proteins and scar tissue [1]. This encapsulation layer increases the distance between the electrode surface and the target tissue, reducing the sensitivity of the device [2]. Blocking of the electrode surface can also affect the electrical properties of the device and surrounding tissue [3].

Deposition of conducting polymers on electrode surfaces has been demonstrated by a number of research groups as a way of controllably modifying electrode-tissue interfaces [4-6]. These conducting polymer modifications can alter the electrode surface properties and functionality, and subsequently affect the biological response to the implanted device. Conducting polymers must be doped with a charged species to maintain charge neutrality, and a range of different dopant ions have been demonstrated [7]. Many of the original dopant ions were small species such as perchlorate or sulfate, or other synthetic polymers such as polystyrene sulfonate. More recently, a number of biologically relevant species have been used to dope conducting polymers [8-11]. Dextran sulfate (DS) is a polysaccharide that is regularly used as an antithrombotic. As a dopant in polypyrrole (PPy), it has been shown to maintain cultured cells [8-10]. The incorporation of this type of biopolymer into an electrode for implantation into human or animal tissue may reduce the level of fouling and encapsulation leading to improved long term performance.

When determining the suitability of an electrode material for neural stimulation, the charge density is typically measured. The charge density defines the amount of charge an electrode delivers per unit area. By increasing the electrode charge density, the size of the implant can be reduced, potentially allowing targeted stimulation of individual neurons and reducing the foreign body response to the implanted device. Platinum is used for most human bionic devices, and the charge density can be determined by hydride reduction and stripping in acidic solutions using cyclic voltammetry [12]. This mechanism is not suitable for most other electrode surfaces, and we recently proposed reduction of a solution soluble redox species, $\mathrm{Ru}\left(\mathrm{NH}_{3}\right)_{6}{ }^{3+}$, as an alternative [13]. Mass transport of the redox species to the electrode surface is affected by voltammetric scan rate, and subsequently, a linear and radial diffusion profile (at fast and slow scan rates respectively) results in two different charge density values; measurement of a geometric area provides a third charge density value. Comparison of each charge density value provides important information on the electrode morphology. By varying the dopant ion, it then becomes possible to tailor electrochemical, morphological and material properties of conducting polymer modified neural electrodes. 
Recently poly-3,4-ethylenedioxythiophene doped with dextran sulfate (PEDOT-DS) was chemically synthesized with electrochemical characterisation in acetonitrile [14]. PEDOT-DS was shown to exhibit good biocompatibility through the adhesion of extracellular matrix proteins and PC12 neuronal cells [15]. To gain a greater understanding of the potential benefits of incorporating DS as a dopant, this study measures the area and charge density of microelectrode arrays modified with electrodeposited PEDOT-DS. The results are compared to PEDOT doped with para-toluene sulfonate (pTs) which displayed a high charge density and good acute recording performance [16].

\section{Experimental}

Dextran sulfate sodium salt (DS, average MW > 500,000), sodium para-toluene sulfonate (NapTs), 3,4ethylenedioxythiophene (EDOT), hexaammineruthenium(III) chloride $\left(\mathrm{Ru}\left(\mathrm{NH}_{3}\right)_{6} \mathrm{Cl}_{3}\right)$ (Sigma-Aldrich) and $99.0 \%$ di-sodium phosphate (Fluka) were used as received. Polymer deposition was on platinum electrodes, 4 shanks of 32 electrodes ( 8 electrodes per shank), $413 \mu \mathrm{m}^{2}$ nominal geometric area with $200 \mu \mathrm{m}$ pitch (Neuronexus Technologies - A4x8-5mm-200-200-413). Conducting polymers with various dopants were deposited electrochemically via a potentiostat (CH660D, CH Instruments) from $10 \mathrm{mM}$ EDOT and $0.1 \mathrm{M} \mathrm{Na}_{2} \mathrm{pTs}$ or $2 \mathrm{mg} \mathrm{mL}^{-1} \mathrm{DS}$ in deionised water. Polymer deposition was conducted in a three-electrode mode using one microelectrode as the working electrode, $\mathrm{Ag} / \mathrm{AgCl}$ ( $3 \mathrm{M}$ $\mathrm{NaCl}$ ) as reference electrode and $\mathrm{Pt}$ mesh as counter electrode. Solutions were degassed with nitrogen for 30 minutes before deposition. Deposition was conducted at $1 \mathrm{~V}$ vs $\mathrm{Ag} / \mathrm{AgCl}$. Potentiostatic growth ensures electrodeposition occurs without allowing the electrode potential to rise above the solvent window, producing unwanted competing reactions which can occur under galvanostatic deposition. Use of a potentiodynamic method provides no benefit over a potentiostatic growth, but would require longer deposition times to form an equivalent deposition charge. PEDOT-DS was deposited at 4 growth periods $(15,30,45$ or $60 \mathrm{~s})$; as recommended previously, PEDOT-pTs was grown for 45s [16]. 2 probes were coated, 4 electrode sites coated at each deposition time in a staggered array as previously described (figure 1) [16], leaving 12 uncoated platinum electrodes and 4 PEDOT-pTS coated electrodes as controls. The electrodes were gently rinsed with deionised water after deposition of the conducting polymer.

Electrodes images were obtained with a BX61 optical microscope (Olympus) and 2 dimensional geometric area measured with ImageJ (figure 1). Electrochemical analysis was performed in $0.3 \mathrm{M}$ phosphate buffer to allow comparison to previous results and the electroactive areas measured by addition of $5 \mathrm{mM} \mathrm{Ru}\left(\mathrm{NH}_{3}\right)_{6}{ }^{3+}$. Test solutions were not degassed to better represent in vivo conditions. A CHI660B potentiostat with CHI684 multiplexer (CH Instruments) were used to perform cyclic voltammetry at each of the individually addressable working electrode sites. A 3 electrode configuration was used with a $\mathrm{Ag} / \mathrm{AgCl}(3 \mathrm{M} \mathrm{KCl})$ reference and $\mathrm{Pt}$ mesh counter electrode. Charge density measurements were performed using cyclic voltammetry over a range of 0.8 to $-0.8 \mathrm{~V}$ vs 
$\mathrm{Ag} / \mathrm{AgCl}$ at a scan rate of $100 \mathrm{mV} \mathrm{s}^{-1}$. Electroactive area measurements were undertaken over a range of 0 to $-0.5 \mathrm{~V}$ varying the scan rate from $10 \mathrm{mV} \mathrm{s}^{-1}$ to $1 \mathrm{~V} \mathrm{~s}^{-1}$.

\section{$3 \quad$ Results and Discussion}

The platinum electrodes were modified as described previously for PEDOT and PPy doped with sulphate, pTs, poly(styrenesulfonate) (PSS), dodecylbenzenesulfonate (DBSA) and chondroitin sulphate (CS) $[11,13,16]$. Uncoated platinum electrodes were bright silver, PEDOT-pTs and PEDOTDS were dark blue (figure 1). In agreement with previous results, PEDOT-pTs deposited for $45 \mathrm{~s}$ uniformly coated the electrode surface. Deposition of PEDOT-DS generated a rougher surface coating similar to PEDOT-PSS and PEDOT-DBSA [13]. The 2 dimensional geometric electrode area measured by optical microscopy had a strong correlation to deposition time (figure 2a). Several of the coatings deposited for $60 \mathrm{~s}$ touched the shank edge, but only the 2 that were at the shank tip displayed a geometric area smaller than expected. A $45 \mathrm{~s}$ deposition of PEDOT-DS produced significantly rougher and larger electrodes than $45 \mathrm{~s}$ deposition of PEDOT-pTs (table 1).

The total deposition charge also increased with time of conducting polymer growth (figure $2 b$ ). Unlike the deposition of PEDOT-DBSA and PEDOT-PSS, no high outliers were observed. These outliers were due to growth of the conducting polymer to the shank edge and expansion of the diffusion field of EDOT monomer to the electrode surface. $45 \mathrm{~s}$ deposition of PEDOT-DS had a significantly larger deposition charge than PEDOT-pTs, but was similar to PEDOT-DBSA and PEDOT-PSS (compare figure $2 \mathrm{~b}$ with reference [13]). The variation in electrode area and growth rate with different dopant ions has been attributed to polymer templating [17].

A correlation of polymer deposition charge and geometric area was seen (figure 3). Only the 2 PEDOTDS depositions for $60 \mathrm{~s}$ at the shank tips displayed significantly lower geometric area than expected. Here, the conducting polymer was able grow around the shank so that the 2 dimensional optically measured geometric area was undervalued.

Cyclic voltammetry of the modified electrodes was performed in $0.3 \mathrm{M}$ phosphate buffer with a potential window from $0.8 \mathrm{~V}$ to $-0.8 \mathrm{~V}$ (figure 4 ). In agreement with previous results, bare platinum electrodes showed a reduction current beginning at $-0.1 \mathrm{~V}$ which extended to $-0.8 \mathrm{~V}$, after switching the potential direction, the current crossed over itself around -0.6 and again at $0 \mathrm{~V}$ (figure 2a) [13]. This process is attributed to irreversible oxygen reduction in the non-degassed solution. PEDOT-pTs voltammetry was also consistent with previous results [16], displaying a relatively featureless response with high capacitance (figure 4a). PEDOT-DS possessed a broad reduction process near - $0.6 \mathrm{~V}$, shifting towards $-0.54 \mathrm{~V}$ on thicker films and small, broad oxidation processes around $-0.5 \mathrm{~V}$ and $-0.25 \mathrm{~V}$ (figure 
$4 b$ ) in agreement with previous results [15]. The background current was larger than PEDOT-pTs but smaller than PEDOT-PSS [13], around $50 \mathrm{nA}$ on the thickest film.

Integration of the current-time plot provides the total charge passed during the potential sweep [18]. The reductive sweep was used as many of the oxidative sweeps passed little or no charge over the tested potential window [16]. One reason for this is that reduction of oxygen is an irreversible process, producing little oxidative current. The reduction of PEDOT-DS is also unlikely to be a fully reversible reaction. Plots of reduction charge versus deposition time revealed 2 groups (figure 5a). The smaller group (less than $-1 \mu \mathrm{C}$ ) has a strong correlation of increased reduction charge with deposition time and is associated with the electrode coatings confined to the top of the shank; the electrode coatings that touch the shank edge displayed larger reduction charges that were more variable. Plotting the reduction charge against the deposition charge produced a strong linear correlation for all coatings confined to the top of the shank (figure 5b). Electrode coatings that touched the shank edge were high outliers and are labelled below the dashed line. The difference in response between electrodes that touch the shank edge to those confined to the shank surface is due to the diffusion field expanding from in front of the shank to include the region on the side and behind the shank. This effect of reduction charge of conducting polymer touching the shank edge (figure 5) is not visible in plots of geometric area and deposition charge versus deposition time (figure 2).

Electroactive area can be determined from the reduction of a dissolved redox active species such as $\mathrm{Ru}\left(\mathrm{NH}_{3}\right)_{6}{ }^{3+}[13]$. The one electron reduction

$$
\mathrm{Ru}\left(\mathrm{NH}_{3}\right)_{6}^{3+}+e^{-} \square \quad \mathrm{Ru}\left(\mathrm{NH}_{3}\right)_{6}^{2+}
$$

at high scan rates on a large, planar electrode, produces a peak shaped voltammetric response with peak current according to

$$
i_{\mathrm{p}}=\left(2.69 \times 10^{5}\right) n^{3 / 2} A D^{1 / 2} C v^{1 / 2}
$$

where $n$ is the number of electrons transferred, $D$ is the diffusion coefficient $\left(9.0 \times 10^{-6} \mathrm{~cm}^{2} \mathrm{~s}^{-1}\right), C$ is the concentration and $v$ is the voltammetric scan rate [13]. At high scan rates (small measurement times), the $\mathrm{Ru}\left(\mathrm{NH}_{3}\right)_{6}{ }^{3+}$ diffusion profile towards the electrode surface is linear. This linear diffusion electroactive area measures all of the conductive regions that $\mathrm{Ru}\left(\mathrm{NH}_{3}\right)_{6}{ }^{3+}$ is accessible to. At slow scan rates (long measurement times), $\mathrm{Ru}\left(\mathrm{NH}_{3}\right)_{6}{ }^{3+}$ must diffuse towards the electrode surface from the solution bulk. At small electrodes or sufficiently long measurement times, a sigmoidal response is seen, and at a disc electrode the steady-state current $\left(i_{\mathrm{ss}}\right)$ is determined from

$$
i_{\mathrm{ss}}=4 n F D C r
$$

where $F$ is the Faraday constant and $r$ is the electrode radius [13]. 
At a scan rate of $20 \mathrm{mV} \mathrm{s}^{-1}$, reduction of $\mathrm{Ru}\left(\mathrm{NH}_{3}\right)_{6}{ }^{3+}$ at a bare electrode showed a sigmoidal response (figure 6a). Background subtraction of the $\mathrm{Ru}\left(\mathrm{NH}_{3}\right)_{6}{ }^{3+}$ voltammetry was used for all electroactive area measurements. A steady-state current of $10 \mathrm{nA}$ is seen with a mid-point potential at $-0.24 \mathrm{~V}$. An average electroactive area of $95 \mu \mathrm{m}^{2}$ was measured from the steady-state current and applying equation 2 (table 1), in good agreement with previous values [13]. PEDOT-pTs displayed a similar response with a typical steady-state current at $17 \mathrm{nA}$ (figure 6a), and an average steady-state electroactive area of $372 \mu \mathrm{m}^{2}$ (table 1). None of the PEDOT-DS modified electrodes displayed a steady-state response with scan rates of 10 or $20 \mathrm{mV} \mathrm{s}^{-1}$ (figure $6 \mathrm{~b}$ ). On the reductive scan, a small peak was always present, and on switching the scan direction, the current crossed over itself, forming a larger reductive peak before approaching $0 \mathrm{nA}$. The lack of a steady-state response indicates the electrodes were very large and slower scan rates (longer times) would be required to achieve a steady-state response. This is consistent with most of the large PEDOT-PSS modified electrodes also not achieving a steady-state response at similar voltammetric scan rates [13].

$\mathrm{Ru}\left(\mathrm{NH}_{3}\right)_{6}{ }^{3+}$ voltammetry at a scan rate of $200 \mathrm{mV} \mathrm{s}^{-1}$ produced peak shaped responses on all electrodes (figure $6 \mathrm{c}-\mathrm{d})$. Uncoated electrodes had reduction peak ( $\left.E_{\mathrm{p}}^{\mathrm{red}}\right)$ at $-0.3 \mathrm{~V}$ and oxidation peak $\left(E_{\mathrm{p}}^{\mathrm{ox}}\right)$ at $0.18 \mathrm{~V}$, with peak separation $\left(\Delta E_{\mathrm{p}}=E_{\mathrm{p}}^{\mathrm{red}}-E_{\mathrm{p}}^{\mathrm{ox}}\right)$ of $120 \mathrm{mV}$ and a mid-point potential ( $\left.E_{1 / 2}=E_{\mathrm{p}}^{\text {red }}+E_{\mathrm{p}}^{\mathrm{ox}} / 2\right)$ of $-0.24 \mathrm{~V}$. A scan rate at $1 \mathrm{~V} \mathrm{~s}^{-1}$ reduced $\Delta E_{\mathrm{p}}$ to $85 \mathrm{mV}$, larger than the expected $60 \mathrm{mV}$, indicating not fully linear diffusion. However, use of scan rates $1 \mathrm{~V} \mathrm{~s}^{-1}$ and higher could not be performed on most electrodes as background capacitance was too large, preventing measurement of the current associated with reduction of $\mathrm{Ru}\left(\mathrm{NH}_{3}\right)_{6}{ }^{3+}$. Calculation of a linear diffusion electroactive area according to equation 1 is not strictly correct on some electrodes; however the highest possible scan rate was used for area calculations to minimise any error associated with radial diffusion, and different electrodes tested using the same method can still be compared [19]. A typical bare electrode had reduction peak current ( $i_{\mathrm{p}}^{\text {red }}$ ) of $9.7 \mathrm{nA}$, the average linear diffusion electroactive area was $418.4 \mu \mathrm{m}^{2}$. PEDOT-pTs had $E_{\mathrm{p}}^{\text {red }}$ of $-0.285 \mathrm{~V}, E_{\mathrm{p}}^{\mathrm{ox}}=-0.18 \mathrm{~V}$, giving a $\Delta E_{\mathrm{p}}=105 \mathrm{mV}$ which decreased to $80 \mathrm{mV}$ when tested at $1 \mathrm{~V} \mathrm{~s}^{-1} \mathrm{scan}$ rate. A typical $i_{\mathrm{p}}^{\text {red }}=23.6 \mathrm{nA}$ was found with an average linear diffusion electroactive area of $1064.8 \mu \mathrm{m}^{2}$. PEDOT-DS showed peaked potentials changing with increased deposition time with typical $E_{\mathrm{p}}^{\text {red }}=-0.295$ to $-0.305 \mathrm{~V}$ and $E_{\mathrm{p}}^{\mathrm{ox}}$ from -0.222 to $-0.258 \mathrm{~V}$, giving $\Delta E_{\mathrm{p}}$ close to $60 \mathrm{mV}$ on all electrodes. $i_{\mathrm{p}}^{\text {red }}$ increased with deposition time with typical values from 44 to $148 \mathrm{nA}$, giving average linear diffusion electroactive areas of 3125.0, 5626.1, 8020.0 and $13846.4 \mu \mathrm{m}^{2}$ (table 1). 
The linear diffusion electroactive areas were plotted against the polymer deposition times, displaying a good correlation (figure 7a). At $45 \mathrm{~s}$ deposition times, PEDOT-DS had a significantly larger electroactive area than PEDOT-pTs. The average values for linear diffusion electroactive area show an increase in effective area in line with deposition time (table 1). Comparison of linear diffusion electroactive area with geometric area also displayed a good correlation for PEDOT-DS (figure 7b).

The charge density $\left(\mathrm{mC} \mathrm{cm}^{-2}\right)$ could then be measured from integrating the reduction current versus time plot and from the geometric or linear diffusion electroactive area. A plot of charge density calculated from the geometric and linear diffusion electrode area showed a correlation across all PEDOT-DS modified electrodes, but not in line with the uncoated and PEDOT-pTs modified electrodes (figure 8), which is in contrast to the results seen with PEDOT-DBSA modified electrodes [13]. Average charge densities calculated from linear diffusion electrode area increase with deposition times, but the charge density calculated from geometric area was more variable with a larger coefficient of variation (table 2). And while the PEDOT-DS average charge density calculated from geometric area was larger than PEDOT-pTs and uncoated electrodes, the average charge densities calculated from linear diffusion area were smaller. Strong correlations are seen of increased charge density with increased area (Figure 9).

Deposition of PEDOT-DS significantly increased the electrode area, and with a $45 \mathrm{~s}$ deposition time, produced geometric areas far greater than PEDOT-pTs and PEDOT-CS and slightly larger than PEDOT-DBSA and PEDOT-PSS [11, 13]. The trend in increased geometric electrode area is in line with the increasing molecular weight of each dopant ion, pTs $<$ DBSA $<$ PSS (MW = 70,000) $<$ DS (MW > 500,000). It has been reported that the change in dopant ion has minimal effect on the solution viscosity, and that variations in electrode size are due to the dopant templating the conducting polymer growth [17]. In this process, the larger dopant ions can direct growth of the PEDOT polymer chains away from the electrode surface towards the bulk solution. This may reduce any blocking of the growing polymer by other polymer chains. During polymer growth, EDOT is oxidised at the electrode surface, lowering its local concentration, which requires diffusion of more monomer to the electrode surface for further polymerisation. Therefore, growth of the conducting polymer into the bulk solution will also reduce the distance from the growing electrode surface to other EDOT monomers. This allows the polymer to grow more rapidly, as demonstrated by the larger deposition charges measured for equivalent times of PEDOT-DS vs PEDOT-pTs (figure 2b).

A variation in conducting polymer morphology has been seen with different dopants [10]. PEDOT deposited on neural implants produced small reproducible disc geometries with pTs; DS, DBSA and PSS dopant ions displayed rough, nodular structures with growth fronts directed along the electrode tracks embedded in the shank. This change in conducting polymer morphology can be expected, as 
deposition of the charged polymer must incorporate a dopant ion to maintain charge neutrality, larger dopant ions require more room, and therefore greater spacing between polymer chains. The large size of the DS dopant ion would make it difficult to eject from the deposited polymer, ensuring that electrode functionality is maintained when implanted into tissue. This type of polymer structure would also ensure that some of the DS dopant ion is exposed to the surrounding solution, and may be of benefit as an antithrombotic, leading to improved biocompatibility of an electrode modified with this material.

The voltammetry of PEDOT-DS displays a large background current with a small non-reversible Faradaic reaction around $-0.5 \mathrm{~V}$, similar to drop cast films [14]. A full description of the impedance spectroscopy of these electrodes will also be published separately. This demonstrates the highly conductive nature and large reductive charge available from this electrode coating. These properties are required for the electrical stimulation of cells. By generating sufficient charge to stimulate a cell from a smaller electrode area, this material also allows the electrode size to be reduced. The foreign body response is also affected by the size of an implanted device [20]. Therefore, as well as the antithrombotic benefits of DS, microelectrodes coated with PEDOT-DS may be able to stimulate individual cells and reduce the immune response to the foreign body.

The electroactive area of different electrode materials gives further information on their roughness and chemical structure. To achieve a steady-state response for the reduction of $\mathrm{Ru}\left(\mathrm{NH}_{3}\right)_{6}{ }^{3+}$ the electrode size must be small enough to enable a convergent diffusion profile. A steady-state response was found on uncoated, PEDOT-CS and PEDOT-DBSA modified Pt microelectrodes but not PEDOT-PSS or PEDOT-DS modified electrodes $[11,13]$. This is consistent with the geometric areas of PEDOT-PSS and PEDOT-DS being significantly larger than PEDOT-pTs. To achieve a steady-state response with PEDOT-DS modified electrodes, significantly slower scan rates would be required, particularly for long film deposition times.

At fast scan rates, all of the electrodes displayed peaked, reversible voltammetry. A linear dependence of peak current with the square root of the scan rate was obtained above $200 \mathrm{mV} / \mathrm{s}$ on most electrodes, indicating a predominantly diffusion controlled process. However a small amount of adsorption may still be present. The application of equation 1 to this system is an approximation that is being used to compare different materials on commonly used neural implants. On the uncoated electrodes, there is clearly a large radial diffusion component still present at $200 \mathrm{mV} \mathrm{s}^{-1}$, therefore scan rates of $600-1000$ $\mathrm{mV} \mathrm{s}^{-1}$ were used to calculate the electrode area. The impact of this radial diffusion decreases after conducting polymer modification as the electrode radius increases, allowing slower scan rates for calculating electrode area. Deposition of the conducting polymer leads to an increase in the relative electroactive area compared to the geometric area due to growth of a rough conducting polymer over a relatively flat bare electrode. The good correlation between electroactive area, deposition time and 
geometric area suggests that lateral resistance plays little part in the results. However, longer deposition times than presented in this work may indeed lead to this behaviour.

The ratio of linear diffusion electroactive area to geometric area was similar between PEDOT-DS and PEDOT-PSS, but larger than PEDOT-DBSA, PEDOT-pTs and bare platinum. This indicates the electrodes are rougher for similar deposition times. PEDOT-DBSA and PEDOT-DS had strong correlations between linear diffusion electroactive area, geometric area and deposition time. However PEDOT-PSS didn't show correlations between these parameters. This difference with PEDOT-PSS is due to greater coefficient of variation in the linear diffusion area values and most likely attributed to the large background current and error in background subtraction. Comparison of PEDOT-DS deposited for $15 \mathrm{~s}$ to PEDOT-pTs deposited for $45 \mathrm{~s}$ can also be undertaken, as they have a similar geometric area. The significantly larger linear diffusion electroactive area for PEDOT-DS indicates it has a much rougher surface.

There was a correlation between the charge density calculated from the geometric and linear diffusion electrode area of PEDOT-DS modified microelectrodes. Once again this is similar to PEDOT-DBSA, while PEDOT-PSS showed no correlation. The ratio of linear diffusion charge density to geometric charge density for PEDOT-DS was different to all the other conducting polymer modified electrodes. So while the electrochemically active electrode area is large, the relative charge that is delivered from the electrode is lower than the other materials. This relatively lower charge injection capacity can be attributed to a smaller capacitance and Faradaic charge value as measured from the voltammograms in Figure 4. Of further interest is the correlation between electrode area and charge density. It is typically assumed that the charge density of a material is independent of its geometry. This may be due to increased radial diffusion at the smaller electrodes or a change in the structure of the conducting polymer as it grows. This finding raises important concerns on the reporting of single charge density values for a material. The ability to increase the charge density of a material by modifying its effective area may have significant impact on improving the performance of neural electrodes.

\section{Conclusions}

Electropolymerisation of PEDOT-DS increases the electrode area, creating a rough morphology similar to other doped conducting polymers. The electrode geometric area is well correlated with deposition time and charge. Voltammetry of PEDOT-DS in a phosphate solution displayed a large background capacitance with small Faradaic processes. The reduction charge was strongly correlated to deposition time and charge, and significantly larger than unmodified or PEDOT-pTs modified electrodes. Reduction of $\mathrm{Ru}\left(\mathrm{NH}_{3}\right)_{6}{ }^{3+}$ at fast scan rates allowed measurement of an electroactive area which strongly correlated to deposition time and geometric area. The electrodes were too large to achieve a steadystate reduction of $\mathrm{Ru}\left(\mathrm{NH}_{3}\right)_{6}{ }^{3+}$ down to voltammetric scan rates of $10 \mathrm{mV} \mathrm{s}^{-1}$. There was a good 
correlation between charge densities calculated from geometric and electroactive areas. The coefficient of variation between electroactive area measures was similar, but the geometric charge density was significantly greater than the linear diffusion charge density. The charge density of the PEDOT-DS modified electrodes was dependant on the electrode area.

\section{Acknowledgements}

Funding from the Australian Research Council Centre of Excellence Scheme (Project Numbers CE0561616 and CE140100012) are gratefully acknowledged. GGW is also grateful to the ARC for support under the Australian Laureate Fellowship scheme (FL110100196). 


\section{References}

[1] G.C. McConnell, et al., Implanted neural electrodes cause chronic, local inflammation that is correlated with local neurodegeneration, Journal of Neural Engineering, 6 (2009) 056003.

[2] P.J. Rousche, R.A. Normann, Chronic recording capability of the Utah Intracortical Electrode Array in cat sensory cortex, Journal of Neuroscience Methods, 82 (1998) 1-15.

[3] W. Grill, J. Thomas Mortimer, Electrical properties of implant encapsulation tissue, Annals of Biomedical Engineering, 22 (1994) 23-33.

[4] X. Cui, J.F. Hetke, J.A. Wiler, D.J. Anderson, D.C. Martin, Electrochemical deposition and characterization of conducting polymer polypyrrole/PSS on multichannel neural probes, Sensors and Actuators A: Physical, 93 (2001) 8-18.

[5] P.M. George, A.W. Lyckman, D.A. LaVan, A. Hegde, Y. Leung, R. Avasare, C. Testa, P.M. Alexander, R. Langer, M. Sur, Fabrication and biocompatibility of polypyrrole implants suitable for neural prosthetics, Biomaterials, 26 (2005) 3511-3519.

[6] K.A. Ludwig, J.D. Uram, J. Yang, D.C. Martin, D.R. Kipke, Chronic neural recordings using silicon microelectrode arrays electrochemically deposited with a poly(3,4-ethylenedioxythiophene) (PEDOT) film, Journal of Neural Engineering, 3 (2006) 59.

[7] B.C. Thompson, S.E. Moulton, R.T. Richardson, G.G. Wallace, Effect of the dopant anion in polypyrrole on nerve growth and release of a neurotrophic protein, Biomaterials, 32 (2011) 38223831.

[8] J.N. Barisci, R. Stella, G.M. Spinks, G.G. Wallace, Characterisation of the topography and surface potential of electrodeposited conducting polymer films using atomic force and electric force microscopies, Electrochimica Acta, 46 (2000) 519-531.

[9] A. Gelmi, M.J. Higgins, G.G. Wallace, Resolving Sub-Molecular Binding and Electrical Switching Mechanisms of Single Proteins at Electroactive Conducting Polymers, Small, 9 (2013) 393-401.

[10] A. Gelmi, M.K. Ljunggren, M. Rafat, E.W.H. Jager, Influence of conductive polymer doping on the viability of cardiac progenitor cells, Journal of Materials Chemistry B, 2 (2014) 3860-3867.

[11] A.R. Harris, P.J. Molino, A.G. Paolini, G.G. Wallace, Effective Area and Charge Density of Chondroitin Sulphate Doped PEDOT Modified Electrodes, Electrochimica Acta, 197 (2016) 99-106.

[12] S.B. Brummer, M.J. Turner, Electrical Stimulation with Pt Electrodes: A Method for Determination of "Real" Electrode Areas, Biomedical Engineering, IEEE Transactions on, BME-24 (1977) 436-439.

[13] A.R. Harris, P.J. Molino, R.M.I. Kapsa, G.M. Clark, A.G. Paolini, G.G. Wallace, Optical and Electrochemical Methods for Determining the Effective Area and Charge Density of Conducting Polymer Modified Electrodes for Neural Stimulation, Analytical Chemistry, 87 (2015) 738-746.

[14] D.G. Harman, R. Gorkin lii, L. Stevens, B. Thompson, K. Wagner, B. Weng, J.H.Y. Chung, M. in het Panhuis, G.G. Wallace, Poly(3,4-ethylenedioxythiophene):dextran sulfate (PEDOT:DS) - A highly processable conductive organic biopolymer, Acta Biomaterialia, 14 (2015) 33-42.

[15] P.J. Molino, Z. Yue, B. Zhang, A. Tibbens, X. Liu, R.M.I. Kapsa, M.J. Higgins, G.G. Wallace, Influence of Biodopants on PEDOT Biomaterial Polymers: Using QCM-D to Characterize Polymer Interactions with Proteins and Living Cells, Advanced Materials Interface, 1 (2014) 1300122.

[16] A.R. Harris, S.J. Morgan, J. Chen, R.M.I. Kapsa, G.G. Wallace, A.G. Paolini, Conducting polymer coated neural recording electrodes, Journal of Neural Engineering, 10 (2013) 016004.

[17] V. Lyutov, I. Efimov, A. Bund, V. Tsakova, Electrochemical polymerization of 3,4ethylenedioxythiophene in the presence of dodecylsulfate and polysulfonic anions-An acoustic impedance study, Electrochimica Acta, 122 (2014) 21-27.

[18] A.R. Harris, S.J. Morgan, G.G. Wallace, A.G. Paolini, A Method for Systematic Electrochemical and Electrophysiological Evaluation of Neural Recording Electrodes, Journal of Visualized Experiments, (2014) e51084.

[19] A.J. Bard, L.R. Faulkner, Electrochemical Methods, 2nd ed., Wiley, New York, 2001. 
[20] T.D. Yoshida Kozai, N.B. Langhals, P.R. Patel, X. Deng, H. Zhang, K.L. Smith, J. Lahann, N.A. Kotov, D.R. Kipke, Ultrasmall implantable composite microelectrodes with bioactive surfaces for chronic neural interfaces, Nat Mater, 11 (2012).

Table 1. Average, standard deviation and coefficient of variation of electrode area measured optically or by reduction of $\mathrm{Ru}\left(\mathrm{NH}_{3}\right)_{6}{ }^{3+}$ for a steady-state or linear diffusion profile electroactive area.

\begin{tabular}{lccccccccc}
\hline Polymer coating & \multicolumn{3}{c}{ Geometric Area $\left(\mu \mathrm{m}^{2}\right)$} & \multicolumn{3}{c}{$\begin{array}{c}\text { Steady-state Electroactive } \\
\text { Area }\left(\mu \mathrm{m}^{2}\right)\end{array}$} & \multicolumn{3}{c}{$\begin{array}{c}\text { Linear Electroactive } \\
\text { Area }\left(\mu \mathrm{m}^{2}\right)\end{array}$} \\
\cline { 2 - 11 } & Ave & SD & CV & Ave & SD & CV & Ave & SD & CV \\
\hline 15s PEDOT-DS & 1004.9 & 92.0 & 0.09 & - & - & - & 3125.0 & 351.5 & 0.11 \\
30s PEDOT-DS & 1565.6 & 128.1 & 0.08 & - & - & - & 5626.1 & 1174.3 & 0.21 \\
45s PEDOT-DS & 2270.5 & 200.1 & 0.09 & - & - & - & 8020.0 & 1305.5 & 0.16 \\
60s PEDOT-DS & 2609.5 & 452.3 & 0.17 & - & - & - & 13846.4 & 4762.1 & 0.34 \\
45s PEDOT-pTs & 794.4 & 105.2 & 0.13 & 372.3 & 100.8 & 0.27 & 1064.8 & 128.1 & 0.12 \\
Uncoated & 420.3 & 16.1 & 0.04 & 94.6 & 19.7 & 0.21 & 418.4 & 39.0 & 0.09 \\
\hline
\end{tabular}

Table 2. Average, standard deviation and coefficient of variation of electrode charge density measured from the background voltammetry reduction charge and geometric, steady-state or linear diffusion profile electroactive area.

\begin{tabular}{lccccccccc}
\hline \multirow{2}{*}{ Polymer coating } & \multicolumn{3}{c}{$\begin{array}{c}\text { Geometric Charge } \\
\text { Density }\left(\mathrm{mC} / \mathrm{cm}^{2}\right)\end{array}$} & \multicolumn{2}{c}{$\begin{array}{c}\text { Steady-state Charge } \\
\text { Density }\left(\mathrm{mC} / \mathrm{cm}^{2}\right)\end{array}$} & \multicolumn{3}{c}{$\begin{array}{c}\text { Linear Charge Density } \\
\left(\mathrm{mC}^{2} \mathrm{~cm}^{2}\right)\end{array}$} \\
\cline { 2 - 11 } & Ave & SD & CV & Ave & SD & CV & Ave & SD & CV \\
\hline 15s PEDOT-DS & 42.8 & 74.3 & 1.73 & - & - & - & 5.3 & 0.3 & 0.06 \\
30s PEDOT-DS & 62.1 & 68.3 & 1.10 & - & - & - & 6.9 & 1.4 & 0.20 \\
45s PEDOT-DS & 36.0 & 26.9 & 0.75 & - & - & - & 7.1 & 0.4 & 0.06 \\
60s PEDOT-DS & 62.8 & 42.4 & 0.68 & - & - & - & 9.5 & 3.0 & 0.32 \\
45s PEDOT-pTs & 21.8 & 2.6 & 0.12 & 48.9 & 13.3 & 0.27 & 16.2 & 1.6 & 0.10 \\
Uncoated & 15.5 & 1.5 & 0.09 & 70.9 & 13.0 & 0.18 & 15.6 & 1.3 & 0.09 \\
\hline
\end{tabular}




\section{Figure Captions}

Figure 1. Optical microscopy of platinum electrodes (a) before and (b-j) after deposition of PEDOT doped with (b) pTs for $45 \mathrm{~s}$ (c-f) DS for 15, 30, 45 and $60 \mathrm{~s}$, (g) whole 32 channel array.

Figure 2. (a) Optically measured geometric electrode area and (b) total deposition charge passed versus deposition time while depositing PEDOT doped with DS or pTs. The two shank tip electrodes modified with a $60 \mathrm{~s}$ deposition of PEDOT-DS have been labelled. The fitted trendline is linear with $95 \%$ confidence interval curves.

Figure 3. Optically measured geometric electrode area versus total charge passed during deposition of PEDOT doped with DS or pTs. The two shank tip electrodes modified with a $60 \mathrm{~s}$ deposition of PEDOTDS have been labelled. The fitted trendline is linear with $95 \%$ confidence interval curves.

Figure 4. Cyclic voltammetry in $0.3 \mathrm{M} \mathrm{Na}_{2} \mathrm{HPO}_{4}$ at $100 \mathrm{mV} \mathrm{s}^{-1}$ of (a) an uncoated electrode and electrode coated with a $45 \mathrm{~s}$ deposition of PEDOT-pTs (b) PEDOT-DS at varying deposition times.

Figure 5. Charge measured from the reductive scan of electrodes in $0.3 \mathrm{M} \mathrm{Na}_{2} \mathrm{HPO}_{4}$ at $100 \mathrm{mV} \mathrm{s}^{-1}$ versus (a) deposition time and (b) total charge passed during deposition of PEDOT doped with DS or pTs. Deposited conducting polymers on electrodes below the dashed lines have touched the edge or tip of the shank and are not included in determining the correlations. The fitted trendline is linear with 95 $\%$ confidence interval curves.

Figure 6. Background subtracted cyclic voltammetry of $5 \mathrm{mM} \mathrm{Ru}\left(\mathrm{NH}_{3}\right)_{6}{ }^{3+}$ in $0.3 \mathrm{M} \mathrm{Na}_{2} \mathrm{HPO}_{4}$ at (a-b) $10 \mathrm{mV} \mathrm{s}^{-1}$ and (c-d) at $200 \mathrm{mV} \mathrm{s}^{-1}$ (a and c) an uncoated electrode and electrode coated with $45 \mathrm{~s}$ deposition of PEDOT-pTs (b and d) PEDOT-DS at varying deposition times.

Figure 7. Comparison of electrochemically measured electrode area versus (a) deposition time and (b) optically measured electrode area of PEDOT doped with DS. Linear diffusion response of $5 \mathrm{mM}$ $\mathrm{Ru}\left(\mathrm{NH}_{3}\right)_{6}{ }^{3+}$ in $0.3 \mathrm{M} \mathrm{Na}_{2} \mathrm{HPO}_{4}$. The fitted trendline is linear with $95 \%$ confidence interval curves.

Figure 8. Comparison of charge density of PEDOT doped with DS with electrode area measured by optical microscopy or linear diffusion response of $5 \mathrm{mM} \mathrm{Ru}\left(\mathrm{NH}_{3}\right)_{6}{ }^{3+}$ in $0.3 \mathrm{M} \mathrm{Na}_{2} \mathrm{HPO}_{4}$. The fitted trendline is linear with $95 \%$ confidence interval curves.

Figure 9. Comparison of charge density and effective electrode area of PEDOT doped with DS (a) optical measured and (b) linear diffusion response of $5 \mathrm{mM} \mathrm{Ru}\left(\mathrm{NH}_{3}\right)_{6}{ }^{3+}$ in $0.3 \mathrm{M} \mathrm{Na}_{2} \mathrm{HPO}_{4}$. The fitted trendline is linear with $95 \%$ confidence interval curves. 


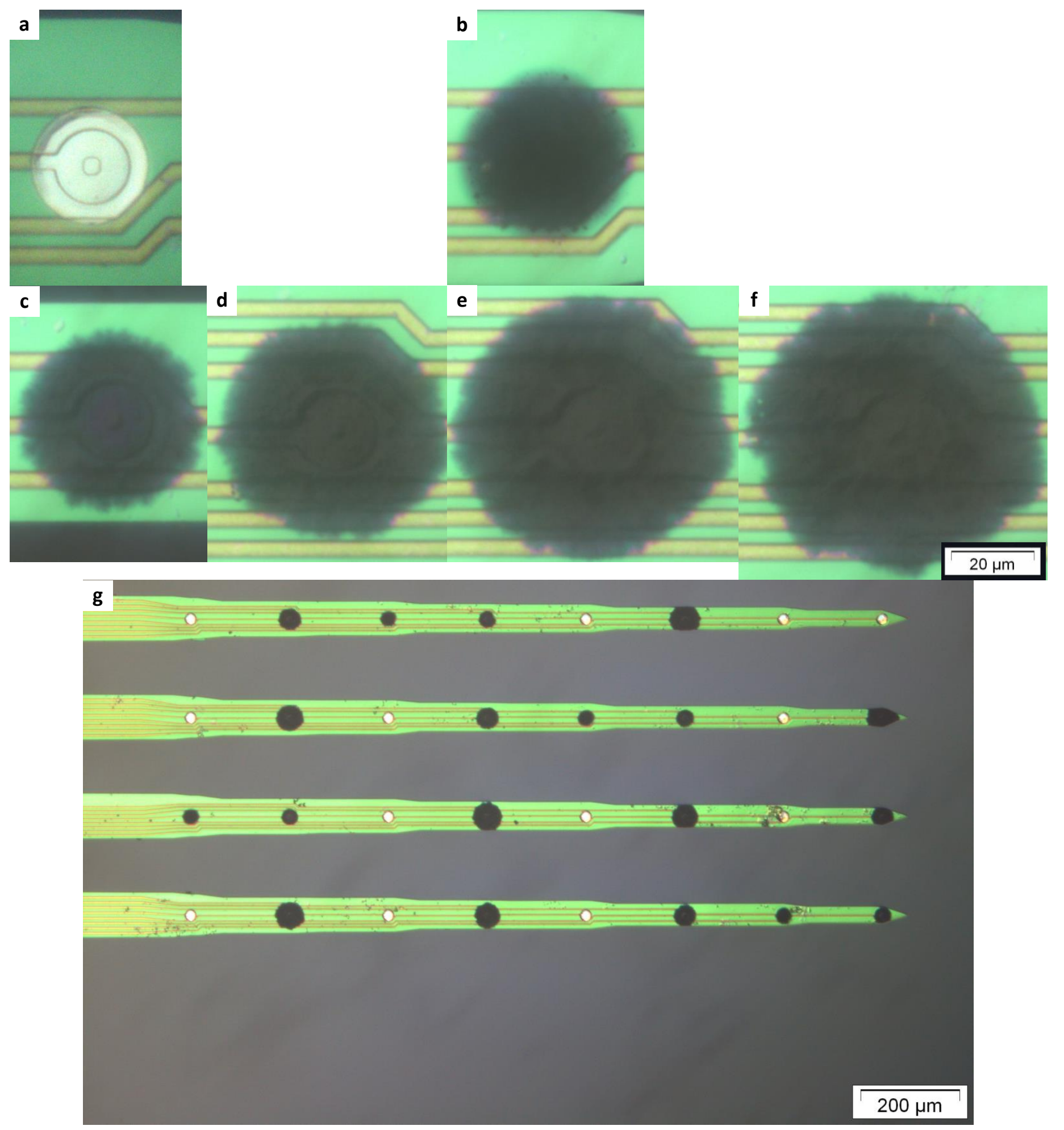

Figure 1 

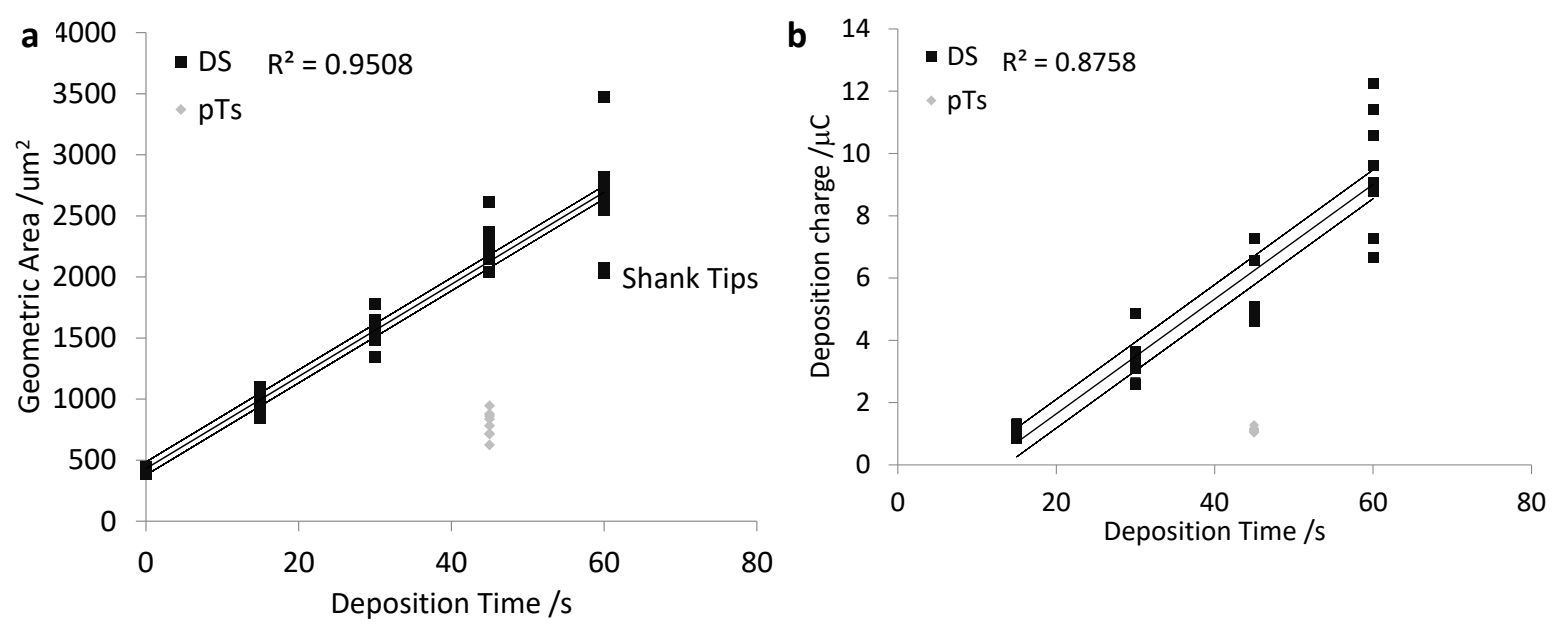

Figure 2

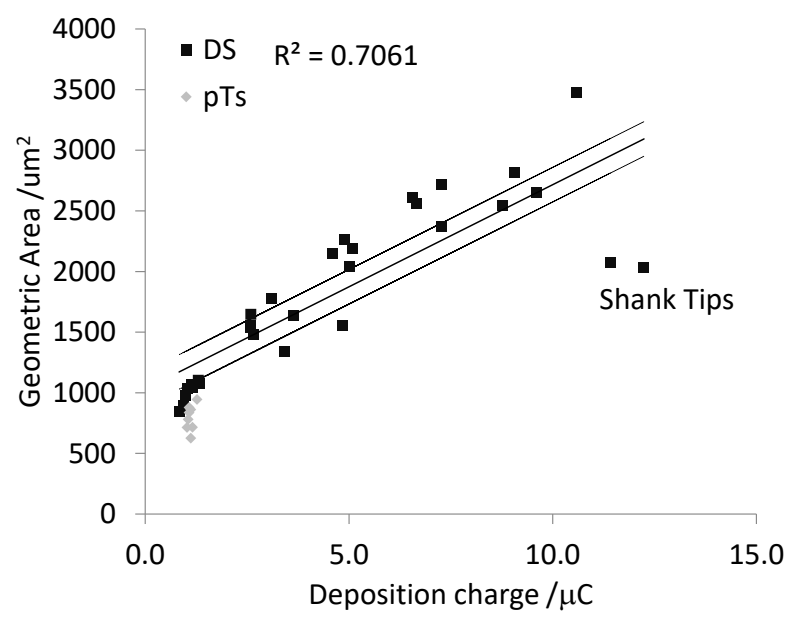

Figure 3

a

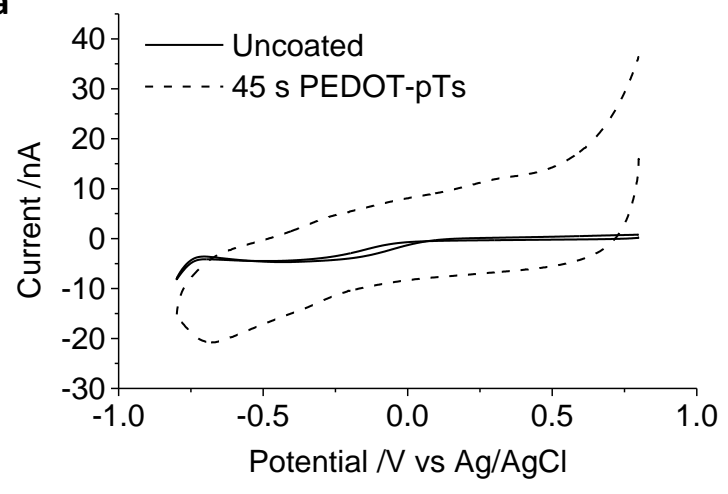

b

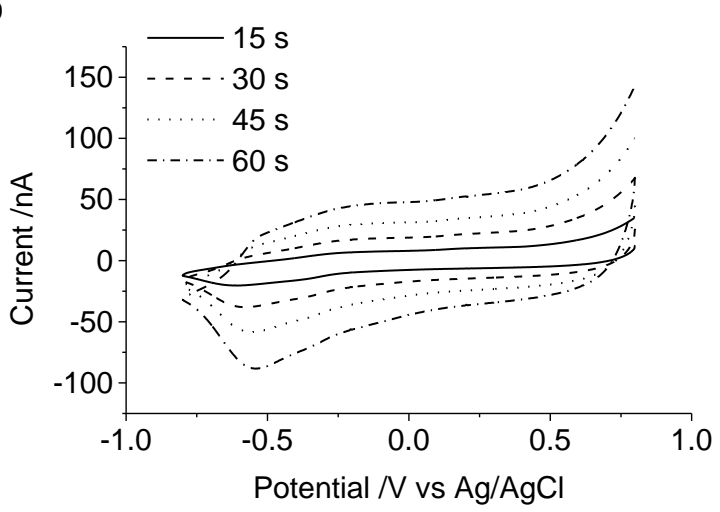

Figure 4 

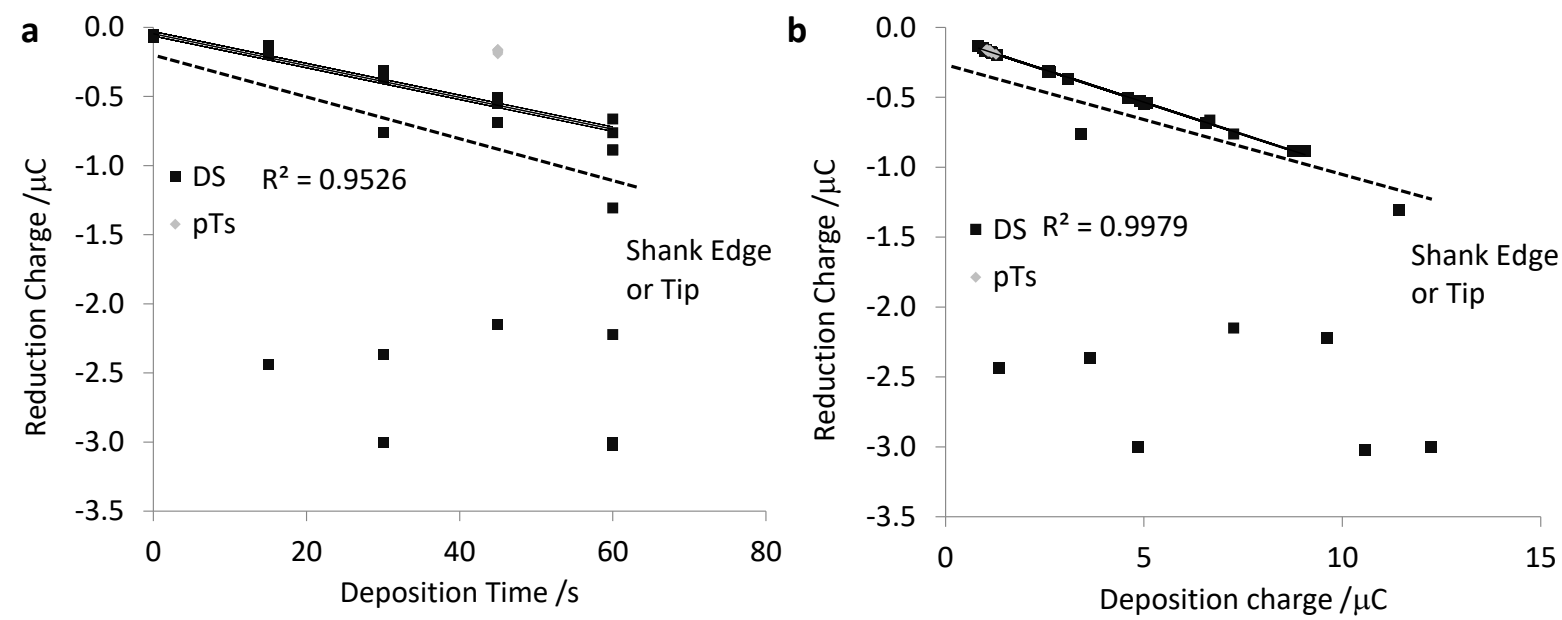

Figure 5

a

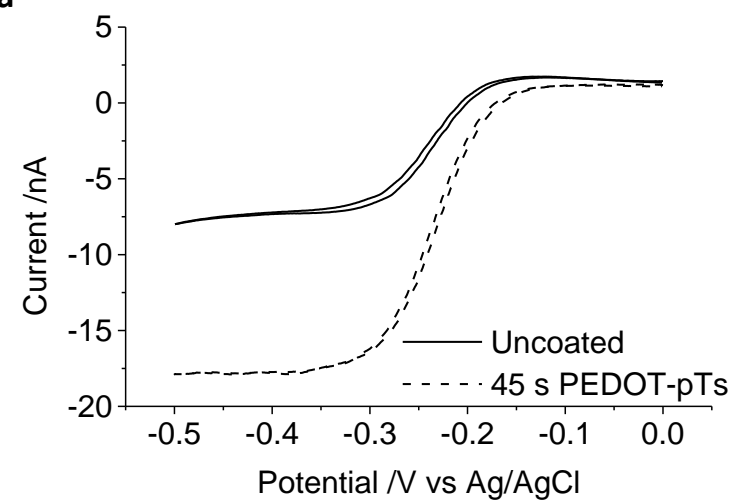

C

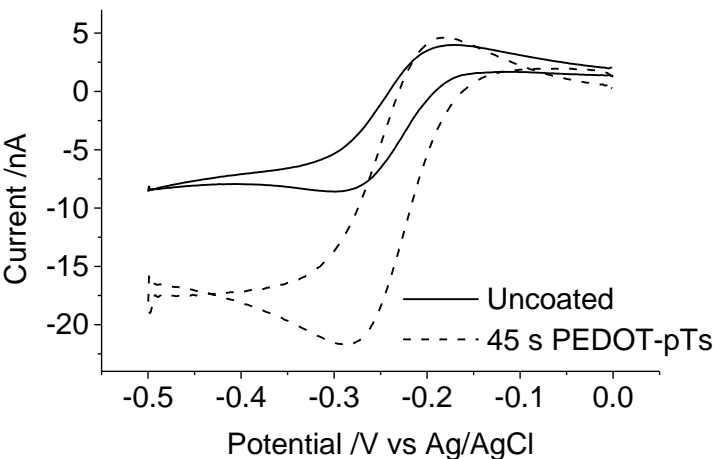

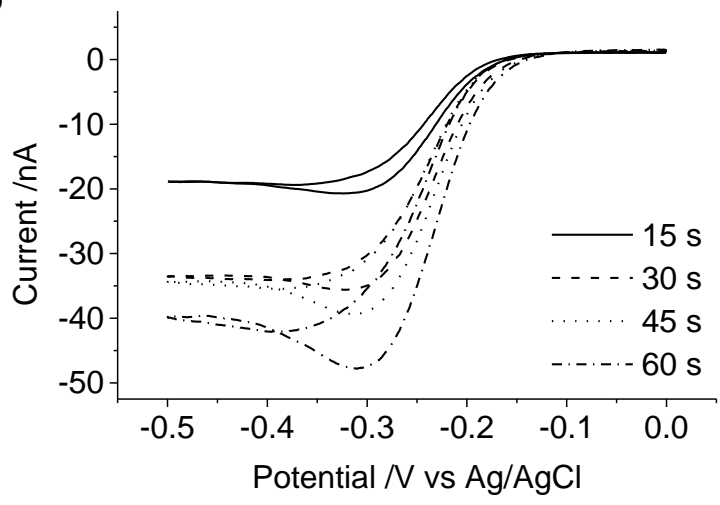

d

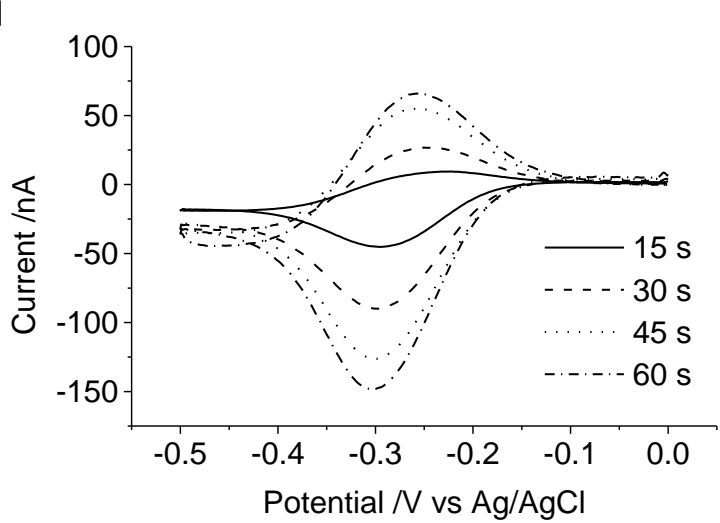

Figure 6 

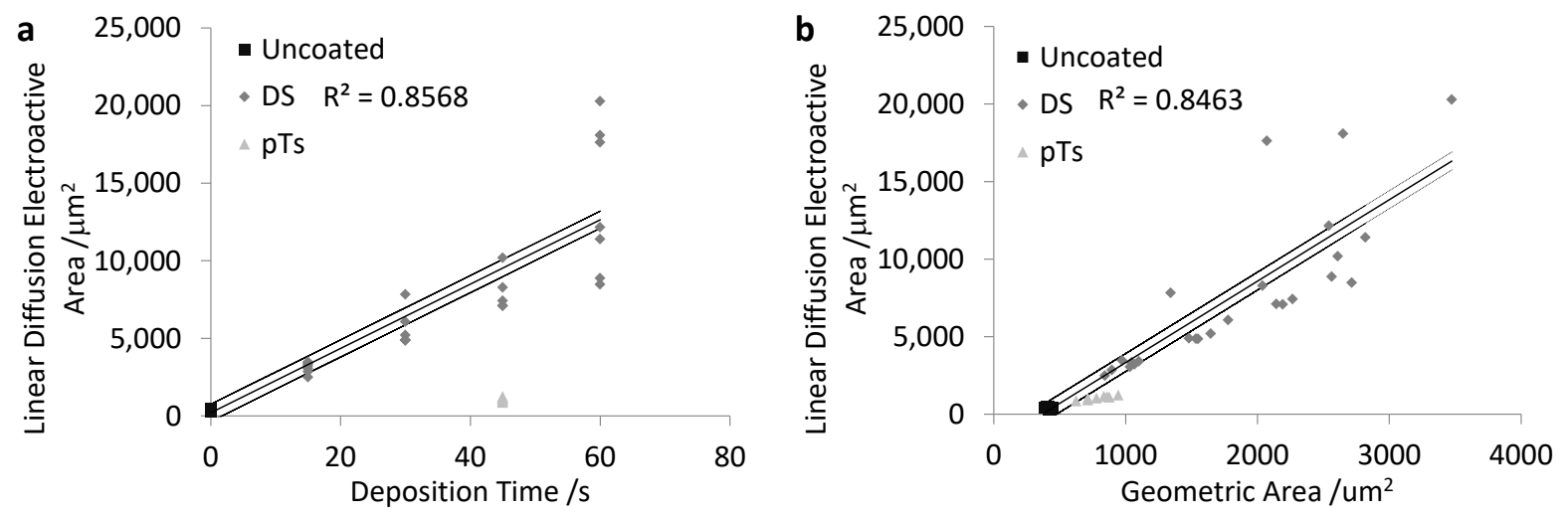

Figure 7

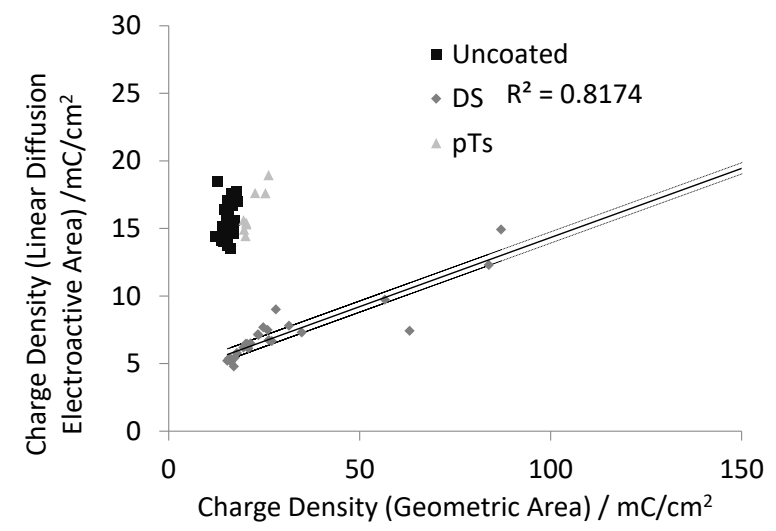

\section{Figure 8}
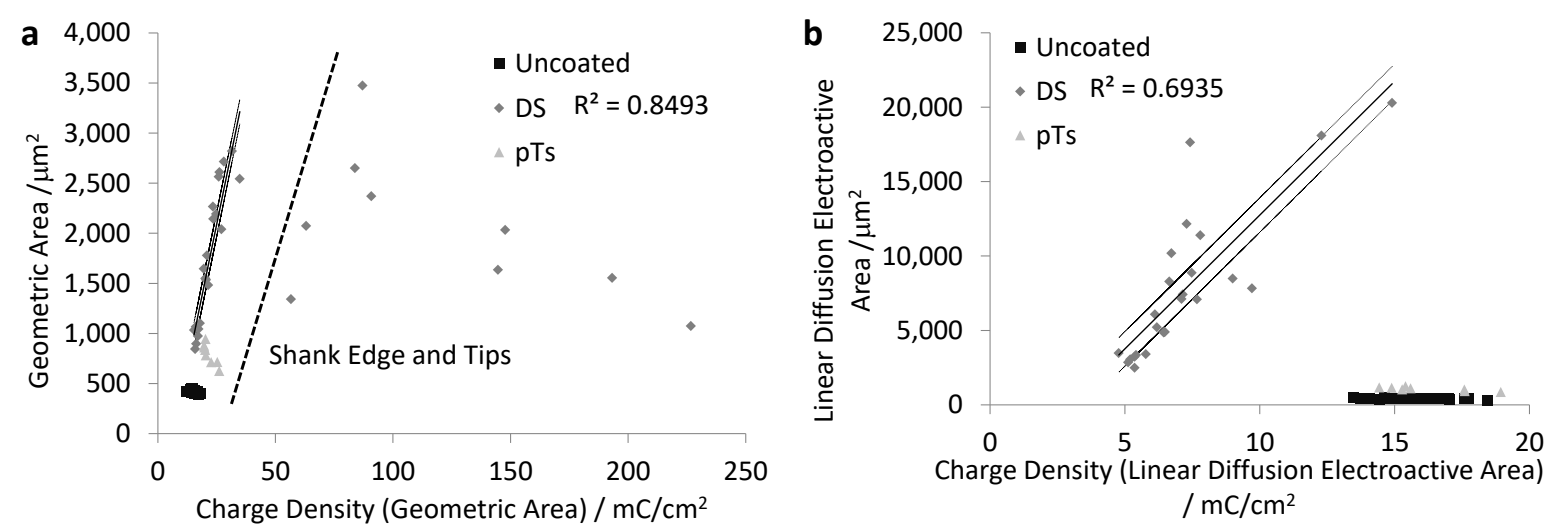

Figure 9 